\title{
Editorial Comment: Randomised Trial of Adjuvant Radiotherapy Following Radical Prostatectomy Versus Radical Prostatectomy Alone in Prostate Cancer Patients with Positive Margins or Extracapsular Extension
}

\author{
Hackman $\mathrm{G}^{1}$, Taari $\mathrm{K}^{2}$, Tammela $\mathrm{TL}^{3}$, Matikainen $\mathrm{M}^{2}$, Kouri $\mathrm{M}^{4}$, Joensuu $\mathrm{T}^{5}$, et al. \\ ${ }^{1}$ Faculty of Medicine, University of Helsinki, Helsinki, Finland; ${ }^{2}$ Department of Urology, Helsinki University Hospital, Helsinki, \\ Finland; ${ }^{3}$ Department of Surgery, Tampere University Hospital, Faculty of Medicine and Life Sciences, Tampere University, \\ Tampere, Finland; ${ }^{4}$ Comprehensive Cancer Center, Helsinki University Hospital, Helsinki, Finland; ${ }^{5}$ Comprehensive Cancer \\ Center, Helsinki University Hospital, Helsinki, Finland; Docrates Cancer Center, Helsinki, Finland
}

Eur Urol. 2019 Nov;76(5):586-595

DOI: 10.1016/j.eururo.2019.07.001 | ACCESS: 10.1016/j.eururo.2019.07.001

Felipe Lott ${ }^{1}$

${ }^{1}$ Instituto Nacional do Câncer - INCA, Rio de Janeiro, RJ, Brasil

\section{COMMENT}

The latest guideline suggest adjuvant radiotherapy or observation following prostatectomy with adverse pathological findings $(1,2)$. This trial randomized 250 patients $(1: 1)$ with pT2NOM0 with positive margins or pT3aNOMO and tries to answer if there is a benefit from adjuvant radiotherapy after radical prostatectomy. The postoperative PSA was less than 0.5. The median follow-up for alive patients was $9.3 \mathrm{yr}$ and $8.6 \mathrm{yr}$ in the adjuvant and in the observation group respectively. The primary endpoint was biochemical recurrence-free survival (BCRFs) and the overall survival, cancer-specific survival, and adverse events were the secondary ones.

The authors founded a 74\% benefit of BCRFs in the adjuvant group, and the number needed to treat was 4. There were no difference in the overall survival and in cancer-specific survival, with more grade 1 and 2 adverse events in the adjuvant group.

The first results of the RADICALS trial (NCT 005541047) recently presented at ESMO Congress 2019 did not show any benefit in BCRFs (secondary endpoint), supporting the use of early salvage radiotherapy. 


\section{CONFLICT OF INTEREST}

None declared.

\section{REFERENCES}

1. Mohler JL, Antonarakis ES, Armstrong AJ, D’Amico AV, Davis BJ, Dorff T, et al. Prostate Cancer, Version 2.2019, NCCN Clinical Practice Guidelines in Oncology. J Natl Compr Canc Netw. 2019;17:479-505.

\section{Felipe Lott, MD}

2. Mottet N, Cornford P, van den Bergh RCN, Briers E, De Santis M, Fanti S, et al. EAU - ESTRO - ESUR - SIOG Guidelines on Prostate Cancer. available at. <https://uroweb.org/guideline/ prostate-cancer> accessed July 11, 2019.

Instituto Nacional do Câncer - INCA

Rio de Janeiro, RJ, Brasil

E-mail:felipelott@hotmail.com

ARTICLE INFO

(iD) Felipe Lott

https://orcid.org/0000-0001-5678-5343

Int Braz J Urol. 2020; 46: 855-6 